\title{
Narrative Representations in Adolescents With Learning Difficulties
}

\author{
Malacrida Marta, Provantini Katia, Mittino Filippo \\ Fondazione Minotauro, Milan, Italy
}

\begin{abstract}
This research develops from clinical practice. Our aim is to provide a precise description of mental functioning of adolescents with learning difficulties (LDs) in order to improve the knowledge of this kind of problems and consequently to get better therapeutic approaches. We focus on narrative representations and we study how these adolescents construct and build stories. We assess 40 adolescents through the use of two kind of tests: Thematic Apperception Test (TAT) and Wechsler Intelligence Scale for Children (WISC-III). In addition, we compare this group with another clinical sample of adolescents. In our sample, learning difficulties are not linked to lower cognitive level, but can be understood as a maturational gap. In the narratives of the adolescents with LDs, we find a typical adolescent narrative: In most cases, the protagonist starts from a position of dependence finally reaching a position of greater autonomy. There are significant differences between the males and females in our sample, which suggest a different mode of learning ability and disability for each sex.
\end{abstract}

Keywords: adolescents, learning difficulties, narrative representations

\section{Introduction}

In the current cultural environment, there is a significant increase in learning difficulties due to many different factors. Specific learning disabilities can be just one of the causes but often scholastic difficulties are the result of many complex symptomatic organizations. We define learning difficulties as a complicated frame in which the most evident symptom is a serious block in the academic and learning abilities: Adolescents with negative academic performances refuse to study despite having the skills to do it or study but collect a series of scholastic underachievements. They also manifest a spectrum of symptoms between various disabling levels of anxiety, a tendency towards isolation, a decline in mood, and a more or less phobic construction that attacks everything that is relevant to the school context or directly the own scholastic itself. This symptomatic set is different from specific learning disabilities (SLD) that means a neurologically-based disorder in one or more of the basic psychological processes involved in learning as understanding or using language, spoken, or written.

In clinical practice, we find that adolescents often express a specific kind of mental pain with learning difficulties. That mental pain needs to be studied in depth and, from this point of view, develops our research. In our work, in fact, we often have met young patients who have negative academic performances and who cannot learn in general, but this learning difficulties were not due to cognitive disabilities or specific learning disabilities.

Malacrida Marta, Psychologist and Psychotherapist, Fondazione Minotauro, Milan, Italy. Provantini Katia, Psychologist and Psychotherapist, Fondazione Minotauro, Milan, Italy. Mittino Filippo, Psychologist and Psychotherapist, Fondazione Minotauro, Milan, Italy. 
Our aim is to develop a precise description of the mental functioning of this type of adolescents in order to improve our knowledge of this kind of problems, to verify our clinical and theoretical hypothesis, and consequently to develop better therapeutic approaches.

\section{Linear and Circular Models}

From current literature, there is not a clear and shared hypothesis that can fully explain the reasons for learning difficulties in adolescents. Nonetheless, we can find a lot of theoretical approaches that focus on several different aspects of learning.

The ability to study is a complicated skill, which involves many factors: cognitive and neuropsychological competence, personality traits, emotional and relational components, self-esteem, and motivation. All these factors are related to each other and interact at different levels.

Several research profects into learning processes have proposed linear causative models to explain the relations between learning difficulties and all other factors involved.

However, circular models have recently been shown to be more suitable because they contemplate a mutual interaction between different cognitive and emotive-relational components: This kind of circular model investigates how all the components are related and interact instead of looking for the "primary" and "secondary" causes (Tressoldi \& Vio, 1996).

\section{Intelligence}

The first factor studied is intelligence. The various research projects do not always show an unitarian or coherent result regarding the real influence of those elements involved in the learning process. The strictly cognitive competences are the only ones that mantain a meaningful and statistically predictive quality during learning perfomances. Some researches, in fact, seem to find the main learning ability predictor in the psychological concept of intelligence (Furnam, Monsen, \& Ahmetoglu, 2009; Freudenthaler, Spinath, \& Neubauer, 2008).

However, this concept seems particularly complicated. Some authors (Lang, 2008), in fact, prefer to talk about "systems, processes, and cognitive abilities" to better define the complexity of the research field. It is well-known the difference between basic intelligence and intelligence in use (Cornoldi, 2007).

This is pointed out by Cronbach (1949) when he describes the difference between what an individual is able to do in a certain learning task (maximal performance) and what effectively he/she will do (typical performance). Following that theorical formulation, we can presume that given the same IQ, several factors may have a specific influence on the learning performance.

\section{Motivation}

Another important theoretical reference is the psychological concept of motivation. Following these theories, cognitive-emotive patterns are more important than the given cognitive outfit. The former regard the learning base process and define origin and direction during learning processes (Dazzi \& Pedrabissi ,2006).

In other words, it is the need which the learning act has to satisfy more than real cognitive competencies that defines the result.

In particular, the authors distinguish two basic standards of learning motivation based on the needs (or emotive-cognitive patterns) from which they originated:

- Intrinsic motivation, meaning the wish to learn as an end in itself supported by knowledge (Berlyne, 1965), know-how (Harter, 1981; White, 1959), or the need for autonomy (Deci \& Ryan, 1985). 
- Extrinsic motivation: This regards external aims and is supported by personal fulfillment needs connected to high social status and achievement of self-esteem (Ausubel, 1978; Nicholls, 1984), parental, teacher, or peer approval (Ausubel, 1978; Deci \& Ryan 1985; Nicholls, 1984). Or as Skinner (1970) stated, motivation is related to the need to receive external reinforcement when learning is conceived as a means to obtaining or avoiding something.

To sum up, from current literature, there is not a clear and shared hyphotesis that can fully explain the reasons for learning difficulties in adolescents. Nonetheless, we can find a lot of theoretical approaches that focus on several different aspects of learning.

\section{Our Hypothesis}

Our theoretical hypothesis develops from clinical practice.

In our work, we found that the best way to interpret and understand the learning difficulties seems to be to include this syndrome in an evolutive theory that consider these adolescents as subjects with a specific growing difficulty. Adolescence, in this theoretical approach, is marked, like other life phases, by typical developmental tasks that the subject has to face. The adolescent has to deal with the mentalizing of the sexualized body, handling distances between himself/herself and the family, building a new system of rules and values, and finally growing up as a social subject (Maggiolini \& Pietropolli Charmet, 2004).

These tasks constitute the process of self-subjectification. We note that adolescents express through learning difficulties an important and more radical developmental setback through learning difficulties. But it appears that the learning processes are the only factor provoking their pain.

At this point, these adolescents seem to be trapped in a complicated psychological process focusing on two specific developmental task. Building the role of student, in fact, represents a specific growth path of this age and must be connected with:

- Separation/identification process: identity construction;

- Social development: The role of student become a more defined social role similar to adult roles (Maggiolini, 1991).

In our clinical practice, in fact, we have often found many adolescents that show a complicated symptomatology with a common hard psychological block preventing them from learning and knowing in general. Following the evolutive theory, it would be necessary that the role of student must now be represented following the principle of power and no longer through infantile omnipotence. This process begins by taking responsibility for modifying, even drastically, one's relationship with the past (Provantini \& Arcari, 2009). Therefore, it becomes essential to assert individuality, the personal ability to do things "by oneselves" in homework as in life, thus asserting separation from the adults and from infantile reference models.

However, these subjects seem to be locked in an eternal present, they cannot introduce new elements into their minds, or think about the future because of an intense mental pain. In these adolescents, we find an anachronistic hanging on to the own infant self (omnipotent), a serious inhibition of: personal reflective function (Fonagy \& Target, 2001) and perceived self-efficacy. A spectrum of symptoms appears between various disabling levels of anxiety, a tendency towards isolation, a decline in mood, and a more or less phobic construction that attacks everything that is relevant to the school context or directly the own scholastic itself.

In an intrapsychic level, we support the hypothesis that an inversion occurs between the superego regulatory function and the ideal ego. This inversion shows up through a short circuit between the ideal image 
of self and that effectively perceived. Indeed, the super ego adjustment function is replaced by the ideal ego which imposes higher performance and behaviour standards. The patient may feel perpetually inadequate and incapable of reaching those standards (Cuccolo, 2012). Inability to mourn for the infant self image leads to the strong desire to identify with it. This identification helps the patient to keep alive the hope of being valuable and recognized as a good student and person. The risk associated with this mechanism is that of becoming trapped in an infant self-representation and in the vicious circle of idealization and mortification of the self (Pietropolli Charmet, 2000).

\section{Target}

The aim of this research is to develop a precise description of the mental functioning of adolescents with learning difficulties in order to improve our knowledge of this kind of problem and consequently to develop better therapeutic approaches. In particularl we try to describe a profile of these adolescents that emphasize which factors are particularly involved (competition, cooperation, self-image, emotional self-regulation, relational approach, etc.). In particular, we focus on the specific way in which these adolescents think, construct, and tell stories and represent themselves and their relationships.

We will describe the results of clinical research into 40 cases of adolescents with learning difficulties that we have in therapy. In addition, we will compare this group with another sample of adolescents in therapy for other kind of disorders.

\section{Sample}

The sample consisted of 40 subjects, 20 girls and 20 boys in therapy for learning difficulties at school in an urban area of Northern Italy. Age ranged from 11 to 17 years old (mean= 14 years old).

\section{Tasks and Measures}

In this research, we use two kinds of tests: Thematic Apperception Test (TAT) and the Wechsler Intelligence Scale for Children (WISC-III).

The Wechsler Intelligence Scale provides a general evaluation of cognitive level that is the most significant predictor of scholastic ability (Furnam et al., 2009; Freudenthaler et al., 2008). Analysis of cognitive skills is important in describing the typical mental functioning of these adolescents (Morelli et al., 2012).

In the TAT protocols, we look for the main representations and the specific internal dynamics of these adolescents. In the clinical setting, we used the TAT as a tool to encourage the production of stories. We consider the TAT story as a narrative pattern through which we are able to observe"what" they tell as well as "how" they tell.

Through the analysis of these stories, we tried to describe the growth stages and identify the main conflicts and the obstacles to development that characterized these adolescents. We therefore focused on the thematic contents of the narratives and the recurring themes that could represent typical patterns.

At the same time, we examined the way the adolescents build the story and their formal features (for example, story plot, characters, and motivational systems).

We refer to narrative semiotics. Its theoretical concepts may be useful for interpreting any narrative text in order to gather the meaning cores, highlighting the subject transformations. 
Many authors (Angus \& Greenberg, 2011; Gonçalves, Matos, \& Santos, 2009; Ferro, 1999; White, 1959; Seganti, 1995) refer to the narratological frame as a mean to study normal and pathological mental functioning. These theoretical approaches seem to arise from a common idea: The self-subjectification is expressed in language that becomes the place par excellence of psychoanalisis (Fornari, 1979). The ability to tell affects the structuring of the self. Stern (1987) stated that the narrative self is the last stage of self-development. Identity is therefore a set of short stories linked each other cronologically (Bruner, 2002). Narrative identity represents the narrative comprehension of the self, which is composed of a synthesis between what the subject is in the present and his/her past history. Narrative perspective is consistent with an evolutive conception of psychoterapy (Maggiolini, 2009), in which the identification of the specific developmental setback it is central. In TAT protocols, we seek the narrative self and the proccess that leads to the construction of narrative identity.

For the TAT scoring, we have two references: Social Cognition and Object Relation Scale (SCORS) of Westen et al. (1991) and Semiotic Analysis Scale (Mittino \& Maggiolini, 2013).

\section{Social Cognition and Object Relation Scale (SCORS)}

The relational objects are conceived by the authors as a multidimensional construction. This one is made up of cognitive and affective development lines that are both interdipendent and distinct and which can be distinguished, according to the different maturity and quality levels, among different individuals as well as in the same individual during lifetime (Westen et al., 1991).

The original version of the tool, with a scale of five ranges, derives from this set.

The purpose of the scale is to measure object-relational/social-cognitive processes or structures that the subject typically manifests. The scale provides scoring criteria for the assessment of the four dimensions of object relations/social cognition from TAT responses:

1. Complexity of representations of people: Scale measures the extent to which the subject clearly differentiates the perspectives of self and others; sees the self and others as having stable, enduring, and multidimensional dispositions; and sees the self and others as psychological beings with complex motives and subjective experience.

2. Affect-tone of relationship paradigms: Scale measures affective quality of representations of people and relationships. It attempts to assess the extent to which the person expects from the world, and particularly from the world of people, profound malevolence or overwhelming pain, or views social interaction as basically benign and enriching.

3. Capacity for emotional investment in relationships and moral standards: Scale measures the extent to which others are treated as ends rather than means, events are regarded in terms other than need-gratification, moral standards are developed and considered, and relationships are experienced as meaningful and committed.

4. Understanding of social causality: Scale measures the extent to which attributions of the causes of people's actions, thoughts, and feelings are logical, accurate, complex, and psychologically-minded.

In addition, there is also a section that contains a list of dominant interpersonal concerns: The clinician has to evaluate which theme is present in every TAT story and has to choose the three most representative.

\section{Semiotic Analysis Scale}

This scale provides an evaluation and description of psychological changes into the narrative texts through the semiotic and narrative approach (Bertrand, 2000; Greimas, 1970, 1983). 
There are for four areas which are evaluated: story plot, characters, trial, and the transformations that occur in the main story.

Story plot includes three variables: story type, motivation, story outcome.

Characters (Greimas \& Courtes, 1979): The clinician has to identify which are the characters present in the story choosing trough subject of the narrative; object to which the subject aims to achieve; sender (who urges the subject to achieve the purpose); helper (who helps the subject); opponent who obstructs the actions of the subject; and recipient (who recognizes the achievement of the purpose).

Each character in the story has to be specified through the affective roles (Fornari, 1977; 1981) that perform. The affective roles bring out the unconscious dynamics that guide the choices and the behaviour of the subject: maternal role; female role; paternal role; adult role; parental role; male role; child role; adolescent role; student role; and fraternal role.

The third part is connected with some peculiar element of the story: The clinician has to evaluate if, in the story, there is a trial and which types of test is it: qualifying test; crucial test; and glorifyng test.

The last area examined is related to the transformation that occurs in the main story. The transformation can be modal (when there has been a shift from inability to ability, from ignorance to knowledge, or from not willing to willing) or seen in the affective evaluation and in the way in which the task is represented.

\section{Results}

\section{Descriptives}

The IQ level of all the adolescents examined is within the normal range (IQ $\min =80$; IQ $\max =131$ ). The IQ mean in our sample is on average level (see Figure 1).

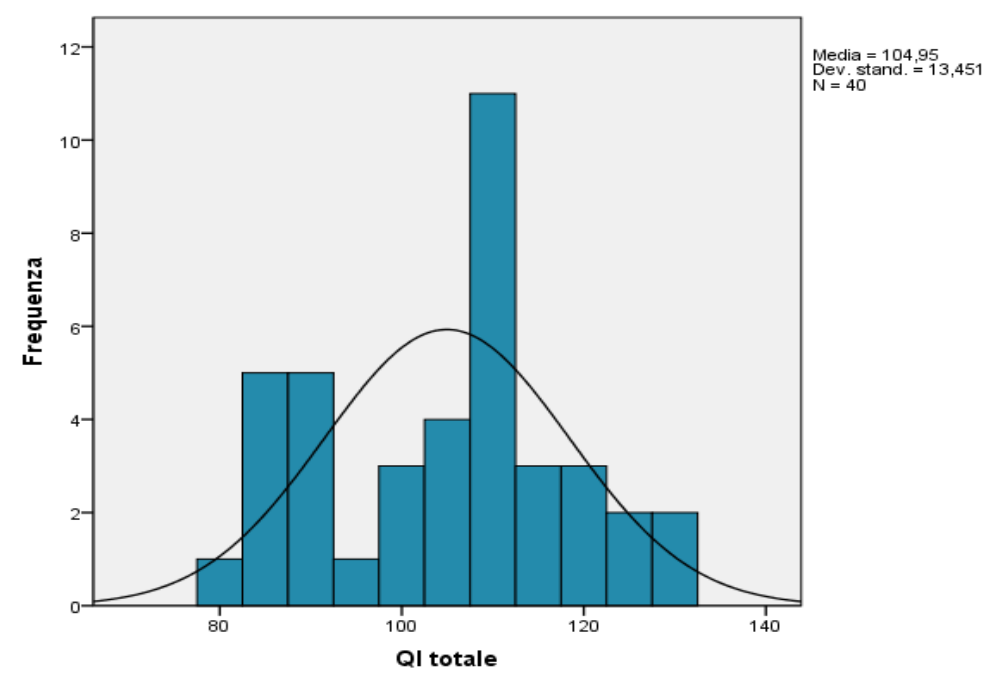

Figure 1. IQ distribution: IQ $\min =80$; IQ $\max =131$; mean $\mathrm{IQ}=105$.

As regards the narrative structure, we find that most of story plots are dynamic (95\%): In almost all the stories, we can observe an evolution of the protagonist instead of a static description of the table.

From the analysis of the affective roles, the data show a typical adolescent narratives: In most cases, in fact, the protagonist starts from a position of dependence (child role, adolescent role, or student role) finally reaching a position of greater autonomy (male role or adult role). 
The motivation that drives the protagonist to move through the story, in most cases, is desire $(54 \%)$ followed by damage to the object (22\%) or its absence (10\%). In $14 \%$ of cases, there is no motivation (see Figure 2).

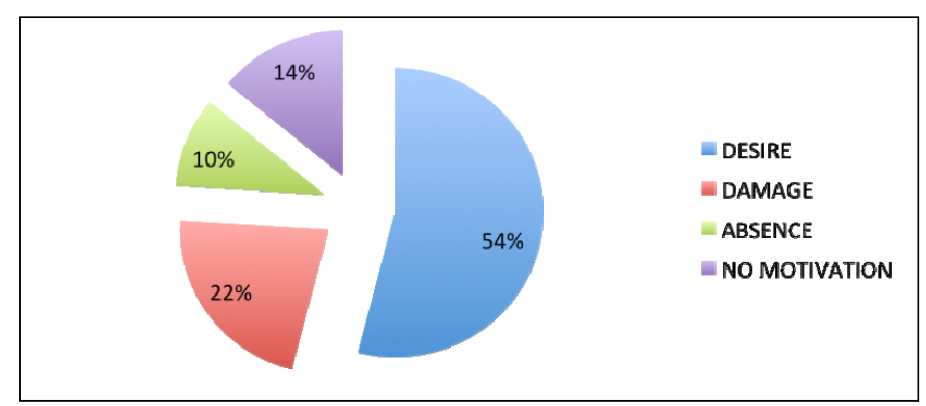

Figure 2. Motivation: desire $=54 \%$; damage $=22 \%$; absence $=10 \%$; no motivation $=14 \%$.

In the story outcome, we can observe how the majority of the stories provides a positive outcome (see Figure 3).

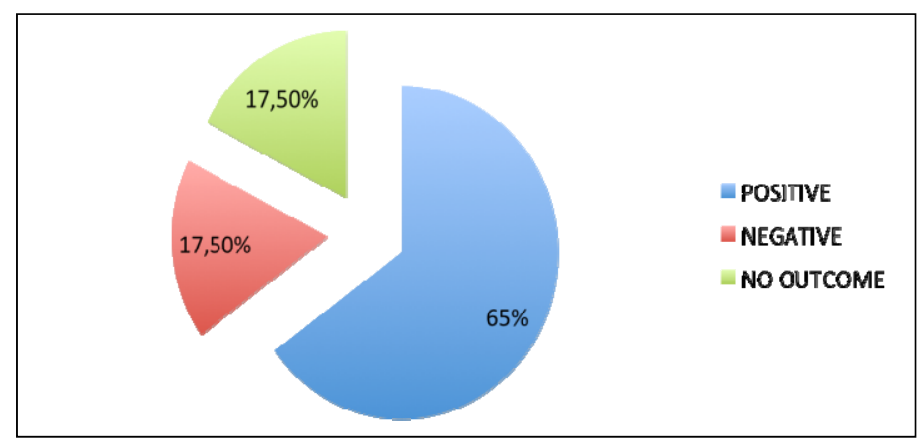

Figure 3. Story outcome: positive $=65 \%$; negative $=17.5 \%$; no outcome $=17.5 \%$.

The most frequent themes are: nurturance (dependence, trust, security, or mentorship, where the relationship is not between peers, and the experience is emotionally positive), autonomy (self-assertion, independent thinking, or pleasure in behaving autonomously), loneliness (isolation, or lack of meaningful relationships which must be distressing to the subject), failure (incompetence or inadequacy), affiliation (friendship, belongingness, or closeness with friends or family), and resignation (characters are resigned or fatalistic) (see Figure 4).

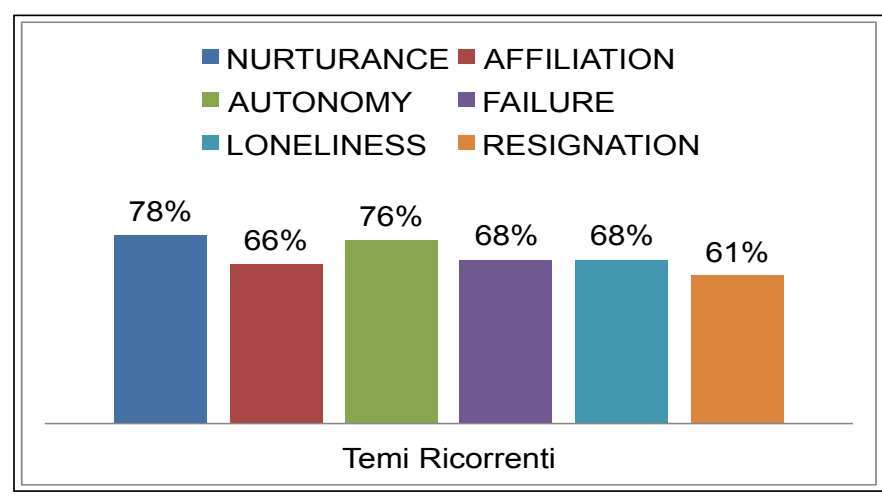

Figure 4. Main themes in the stories: nurturance $=78 \%$; autonomy $=76 \%$; failure $=68 \%$; loneliness $=68 \%$; affiliation $=66 \%$; resignation $=61 \%$. 


\section{Gender}

Results show significant gender differences in narrative patterns.

We assessed the ability to tell and construct stories and we also tried to distinguish between good and bad competence in this task. So, we isolated two types called "good storytellers" and "bad storytellers" based on the average score obtained by the subject in the four scales of the scors instrument.

Girls seem to be more frequently "good storytellers": They are able to construct articulated and elaborated plots; they represent characters and relations in a complicated way with better affective tone (see Figure 5).

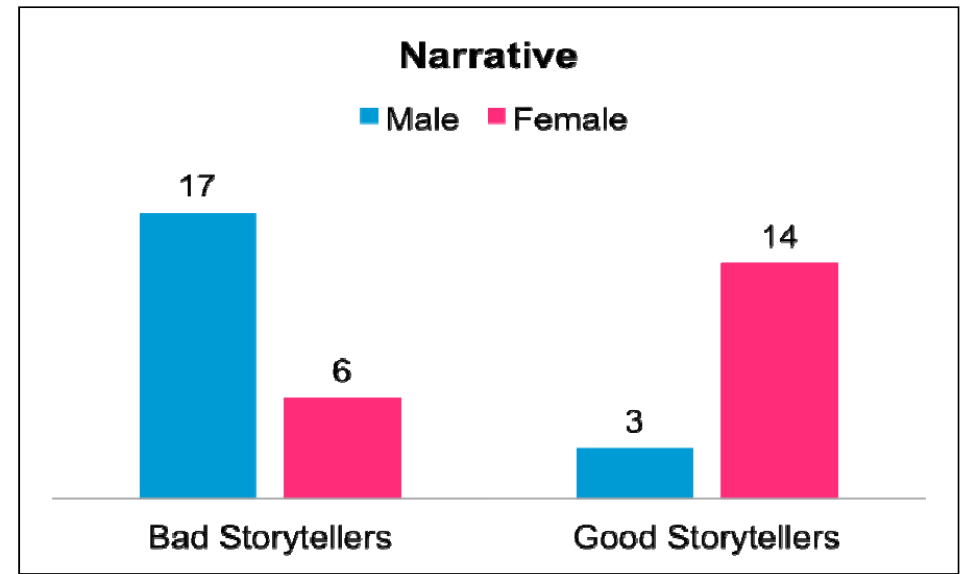

Figure 5. Bad storytellers: male $17 \%$, female $6 \%$; good storytellers $=$ male $3 \%$, female $14 \%$; Chi-square $=12.37, p=0$.

We performed the Chi-square test on gender and on all the features of narrative structure of Semiotic analysis scale and characters. The data show that there is a significant difference in the variable "Transformation": boys usually tell more stories in which there are transformations. Boys also tend to be less confident with helpers than girls. In other words boys ask for less help than girls, but they tend to accept change more easily (see Figure 6).

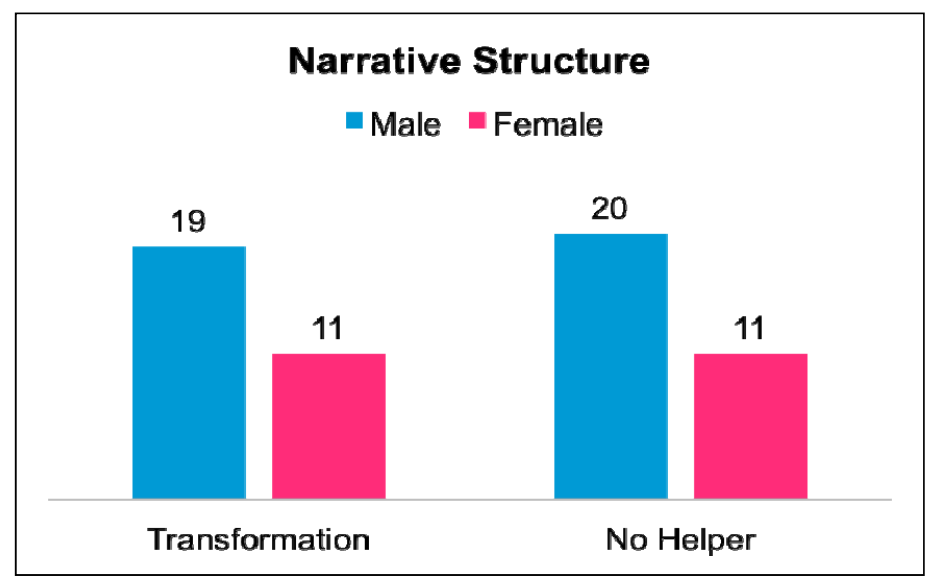

Figure 6. Transformation: Male 19\%/Female $11 \%$, Chi-square $=8.5, p<0.01$; no helper: Male $20 \% /$ Female $11 \%$, Chi square $=11.6, p<0.01$

Referring to dominant interpersonal concerns (main themes), we find a significant difference in gender dealing with themes of failure and loneliness. Failure predominates in the stories told by the girls while loneliness is more typical of boys' themes (see Figure 7). 


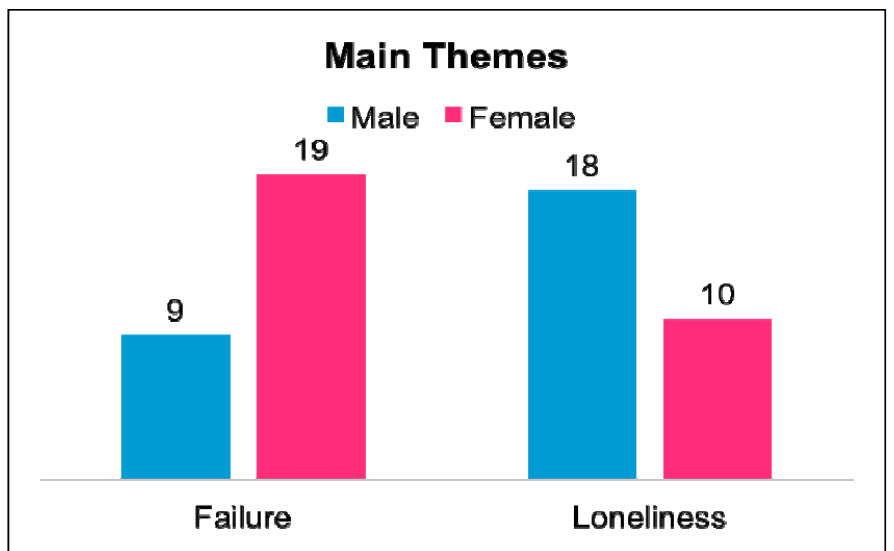

Figure 7. Failure: male $9 \%$, female $19 \%$, Chi-square $=11.9, p=0,001$; Loneliness: male $18 \%$, female $10 \%$; Chi-square $=7.6, p=0.005$.

There are some important differences in the narrative structure of males and females: Boys seem to struggle to express their discomfort and tend to live this situation in loneliness. In their stories, however, there are more transformations, so they think that change is possible but often do not know how it is possible. For their transformation, in fact, they do not ask for support. Girls talk about their discomfort more easily, reporting stories that have failure as the main theme. Transformation, however, is less present in their narrative, as if their narrative ability were not enough to make change possible.

\section{Comparison With Another Clinical Sample}

We compared our sample (LD) with another clinical sample of adolescents in therapy for other types of disorders (MP) in order to find out which are the differences in terms of story-telling, thematic contents, and narrative patterns. This sample consists of 30 adolescents ( 15 boys and 15 girls), aged 12-19 (mean = 16 years old).

\section{Narrative Structure}

In both samples, we observe a typical narrative structure. Affective role analysis, in fact, confirms a specific evolutive narrative pattern: Most of the stories develop from an initial position of dependence through a process which achieves a greater level of autonomy. However, in the learning difficulties (LDs) sample, the subject (protagonist) is more frequently an adolescent, while in the mixed pathology (MP) sample is a child (see Figure 8).

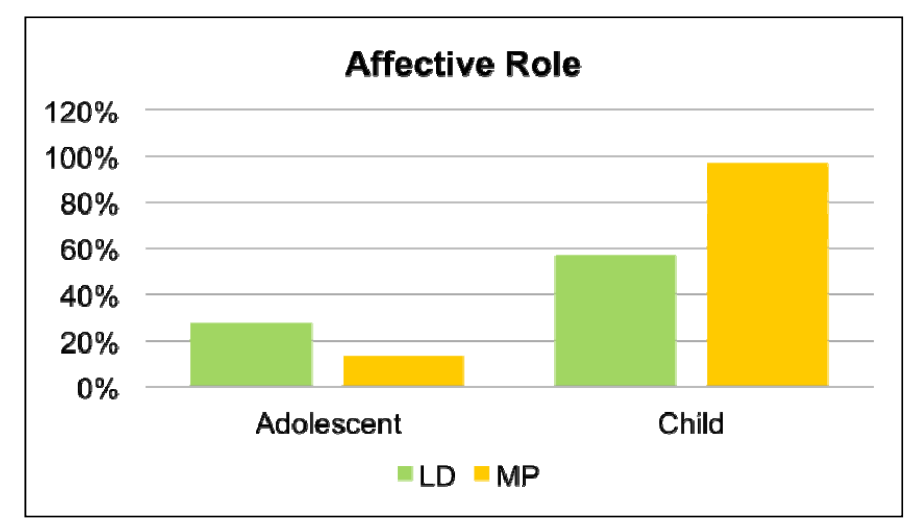

Figure 8. Chi-square $=22.531, p<0.05$. 
The stories are dynamic, but the basic motivation which action starts from is different: In the LD sample, it is desire, while in the MP sample, it is the absence of the object (see Figure 9).

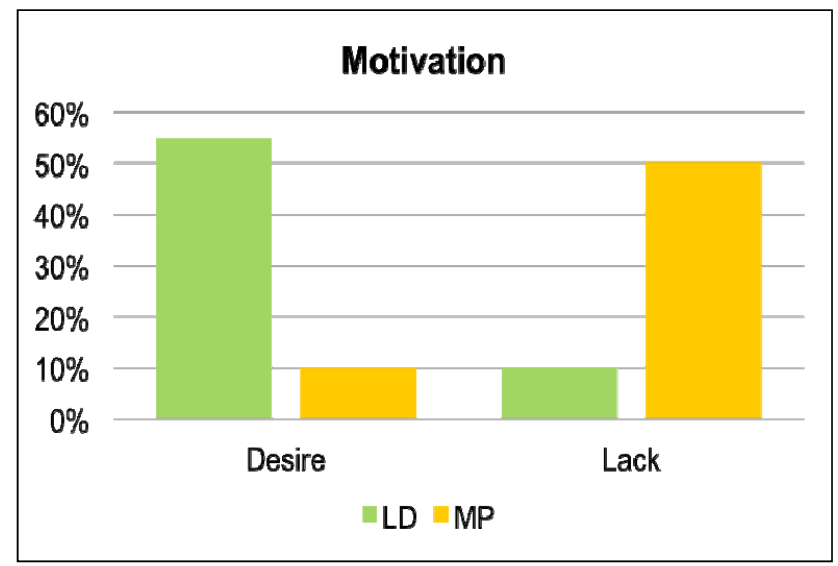

Figure 9. Chi-square $=30.369, \mathrm{p}<0.001$.

The story outcome is positive in the LD sample more often than in the MP sample (see Figure 10).

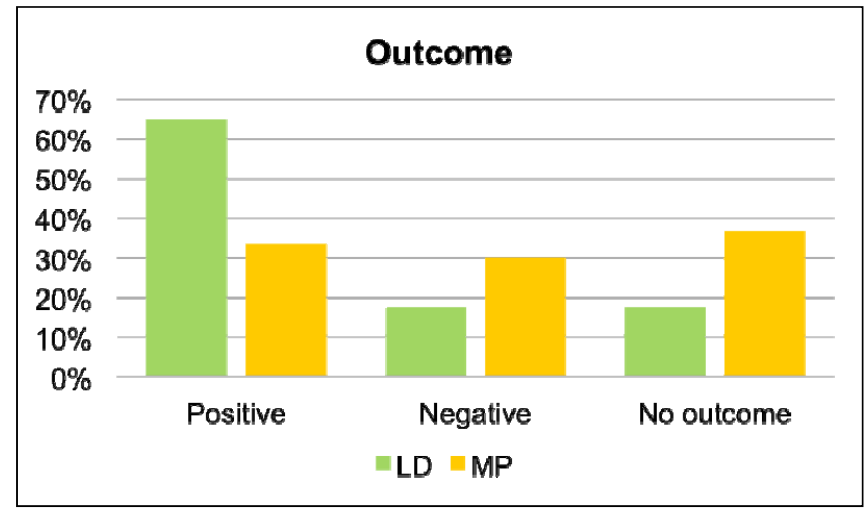

Figure 10. Chi-square $=6,964-\mathrm{p}<0,05$.

\section{Dominant Interpersonal Concerns}

There are some thematic contents that are more frequent in LD sample (autonomy, identity, helplessness, and loneliness), while in the other sample, the data show a significant statistical difference between theme of fears about safety, survival, protection, and suicide (see Figure 11).

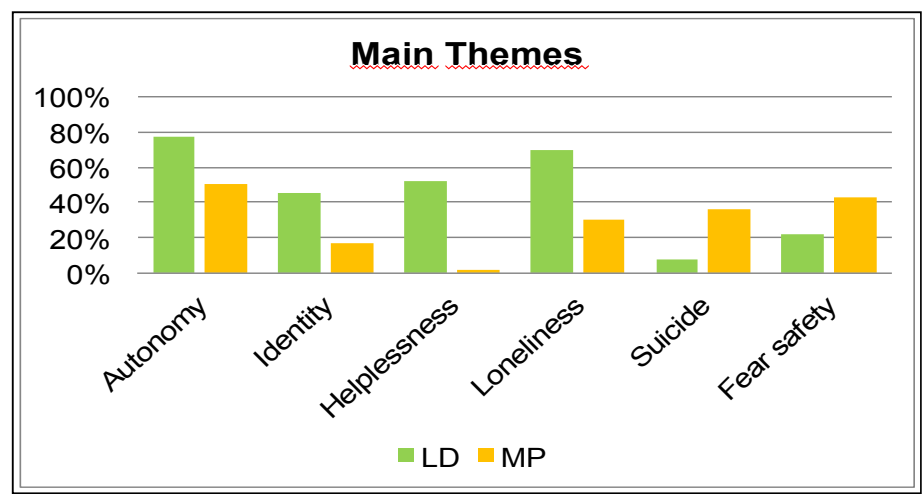

Figure 11. Frequency of dominant interpersonal concern. 


\section{Discussion}

The results confirm the hypothesis of a correlation between learning difficulties and growth dynamics. Adolescents with learning difficulties seem to be deeply trapped in their separation-individuation process. More frequent themes in our sample concern evolutive patterns and affects connected to binomial dependence/autonomy, as if their mental representations were specifically connected with this dynamic.

The second important element is the process of hiring social dimension. Following more frequent themes, indeed, there are negative affects, like failure, loneliness, and resignation that seem to represent simultaneously the outcome of an unfinished process of separation and a difficult process of socialization. This evidence is also confirmed by the final theme characterizing narratives of learning difficulties sample (affiliation, friendship, belongingness, or closeness with friends or family) which is the most relational of the themes.

This is also confirmed by comparison with the other sample. Adolescents with learning difficulties choose as the subject (as well as the object of identification) an adolescent role (or student role); they tell stories in which there is desire as motivation and which end with a positive outcome.

They seem to be perfectly placed in a developmental dimension. However, the block is in the difficulty, which sometimes becomes even impossibility, to reach the desired outcome: In the stories, as we have said, there is desire and a positive outcome, but in most cases, there is no transformation.

In other words, adolescents often know where they would like to get to, but they do not know how to get there. They cannot represent and concretely decline change; they fail to plan all the intermediate steps necessary to achieve the purpose.

In the narratives, we often find a sort of redemptive sequence in which bad turns to good, but without explanation or proper description. The transformation seems to be magic and there is very little reflective activity in making the change from negative to positive. This could concretely represent their mental functioning: They know where they want to get, they know how to identify the targets (which are often too high because dictated by the IdealEgo), but often they have to stop because they cannot imagine the process that leads them to their goal.

This psychological mechanism leads to avoidance, renouncing, and escape into fantasy where the desire is confined.

As we said, narrative structures are similar for both samples. We note that this phenomenon may be related to the presence of a sort of typical adolescent narrative structure in which the transition from dependence to autonomy is a crucial element. While the narrative structure is common, the thematic contents are what really distinguish the narratives.

The prevalent themes, in the MP sample, are characterized by more serious issues, such as fears about safety, survival, or protection and death. The LD themes, on the other hand, are more often characterized by evolutive contents, such as identity construction, achievement, and autonomy or relational contents, like social and interpersonal success. Other themes typical of the LD sample (helplessness) together with failure refer to self-esteem, identity, and self-efficacy, as if the underlying fear was to experience self-mortification rendering their inadequacy visible.

Overall, the hypothesis is that adolescents with LD are engaged in a particular way in a psychological process revolving around the fundamental questions "Who am I?" and "Who do I want to be?" in a personal and social declination. The developmental block seems to be placed at this stage and manifests itself through the learning inabilty. 
At the same time, this block appears at a more superficial level and consequently may be less debilitating than other sets of symptoms in which mental pain and psychic impairment could be deeper. Our hypothesis, supported also by many years of clinical practice, is that the greatest risk for LD adolescents is the formation of obsessive conducts and phobic structures without a more serious attack against the self.

\section{Limitations and Conclusions}

Our future aim is to broaden the research in order to verify these initial results. The first step is to compare our sample with a group of adolescents with specific learning disabilities.

We also intend to insert more precise anamnestic variables in the analysis in order to verify if there is a correlation between the moment in life in which learning difficulties emerged and the evolutive narrative representations.

\section{References}

Abbate, L., \& Massaro, V. (2007). La valutazione delle relazioni oggettuali e delle rappresentazioni sociali con il TAT. Milano: Raffaello Cortina.

Angus, L., \& Greenberg, L. (2011) Working with Narrative in Emotion-focussed Therapy: Changing stories, healing lives. Washington, D.C.: American Psychological Association Press.

Ausubel, D. P. (1978). Educazione e processi cognitivi. Guida psicologica per gli insegnanti. Milano: Franco Angeli.

Berlyne, D. E. (1965). Curiosity and education. In J. D. Krumboltz (Ed.), Learning and the educational process (pp. 67-89). Chicago. IL: Rand Mc Nally and Company

Bertrand, D. (2000). Précis de sémiotiquelittéraire. Paris. Tr. It. Basi di semiotica letteraria. Milano: Meltemi.

Bruner, J. S. (2002). La fabbrica delle storie: Diritto, letteratura, vita. Bari: Laterza.

Cornoldi, C. (2007). Le basi cognitive dell'intelligenza. Giornale Italiano di Psicologia, (2), 267-269.

Cronbach, L. J. (1949). Essentials of psychological testing. New York: Halpern.

Cuccolo, D. (2012). Compiti evolutivi e difficoltà di apprendimento. Il laboratorio clinico come proposta di intervento. AeP Adolescenza e Psicoanalisi, VII(2).

Dazzi, C., \& Pedrabissi, L. (2006). Motivazione intrinseca ed estrinseca e disagio scolastico: Un contributo alla validazione del test “Perché studio?". Psicologia Clinica e Dello Sviluppo, (2), 209-224.

De Beni, R., \& Moè, A. (2000). Motivazione e apprendimento. Il Mulino: Bologna.

Deci, E. L., \& Ryan, R. M. (1985). Intrinsic motivation and self-determination in human behaviour. New York: Plenum Press.

Ferro, A. (1999). La psicoanalisi come letteratura e terapia. Milano: Raffaello Cortina.

Fonagy, P., \& Target, M. (2001). Attaccamento e funzione riflessiva. Milano: Cortina.

Fornari, F. (1977). Dalla Traumdeutung all'analisi coinemica. Milano: Unicopli.

Fornari, F. (1979). I fondamenti di una teoria psicoanalitica del linguaggio. Torino: Bollati Boringhieri.

Fornari, F. (1981). I sogni delle madri in gravidanza: le strutture affettive del codice materno. Collana: Materiali universitari. Psicologia, 1, Milano: Unicopli.

Freudenthaler, H., Spinath, B., \& Neubauer, A. C. (2008). Predicting school achievement in boys and girls. European Journal of Personality, 22, 231-245.

Furnam, A., Monsen, J., \& Ahmetoglu, G. (2009). Typical intellectual engagement: Big Five personality traits, approaches to learning and cognitive ability predictors of academic performance. British Journal of educational Psychology, 79, $769-782$.

Gonçalves, M. M., Matos, M., \& Santos, A. (2009). Narrative Therapy and the nature of "innovative moments" in the construction of change. Journal of Constructivist Psychology, 22, 1-23.

Greimas, A. J. (1970). Du sens. Tr. It. Del senso. Milano: Bompiani.

Greimas, A. J. (1983). Du sens II. Essaissémiotiques. Tr. It. Del senso II. Narrativa, modalità passioni. Milano: Bompiani.

Greimas, A. J., \& Courtes, J. (1979). Semiotica. Dizionario ragionato della teoria del linguaggio. Milano: Mondadori.

Harter, S. (1981). A new self-report scale of intrinsic versus extrinsic orientation in the classroom: Motivational and informational components. Developmental Psychology, 17(3), 300-312.

Lang, M. (2008). Le scale Wechsler per adulti. Valutazione delle funzioni cognitive e analisi del processo. Milano: Raffaello Cortina. 
Liotti, G., \& Monticelli, F. (2008). I sistemi motivazionali nel dialogo clinico. Il Manuale AIMIT. Milano: Raffaello Cortina.

Ludolph, P., Westen, D., Lerner, H., Ruffins, S., \& Wiss, F. C. (1990). Object relations in borderline adolescents. Journal of the American Academy of Child and Adolescent Psychiatry, 29(3), 338-348.

Maggiolini, A. (1991). Ruoli affettivi e adolescenza. Milano: Unicopli.

Maggiolini, A. (2009). Ruoli affettivi e psicoterapia. Il cambiamento come sviluppo. Milano: Raffaello Cortina.

Maggiolini, A., \& Pietropolli Charmet, G. (2004). Manuale di Psicologia dell'adolescenza: compiti e conflitti. Milano: Franco Angeli.

Mittino, F., \& Maggiolini, A. (2013). Analisi narrativa di TAT di un campione di adolescenti. Psichiatria e Psicoterapia, (1), 42-58.

Morelli, M., Malacrida, M., Riccelli, F., Maggiolini, M., Provantini, K., \& Chirumbolo, A. (2012). Difficoltà di apprendimento, intelligenza e psicopatologia. Una ricerca su preadolescenti e adolescenti in difficoltà a scuola. Poster presentato $10^{\circ}$ Convegno Nazionale dei Gruppi Nazionali di Psicoterapia Psicoanalitica dell'Adolescenza AGIPPsA: Adolescenza e Psicoanalisi Oggi, 13-14 ottobre, Roma.

Nicholls, J. G. (1984). Conceptions of ability and achievement motivation. In R. E. Ames and C. Ames (Eds.), Research on motivation in education (Vol. 1). Orlando, FL: Academic Press

Pietropolli Charmet, G. (2000). I nuovi adolescenti. Milano: Raffaello Cortina.

Pietropolli Charmet, G. (2009). Fragile e spavaldo. Ritratto dell'adolescente di oggi. Roma: Laterza.

Provantini, K., \& Arcari, A. (2009). La scelta giusta. Orientarsi dopo la terza media. Milano: Franco Angeli.

Seganti, A. (1995). La memoria sensoriale delle relazioni. Ipotesi verificabili di psicoterapia psicoanalitica. Torino: Bollati Boringhieri.

Silk, K. R., Westen, D., Ludolph, P., Kellam, A., Gold, L., \& Lohr, N. (1990). Object relations in borderline adolescents and adults: Developmental differences. Adolescent Psychiatry, 17, 360-384.

Skinner, B. F. (1970). La tecnologia dell'insegnamento. Brescia: La Scuola.

Stern, D. N. (1987). Il mondo interpersonale del bambino. Torino: Bollati Boringhieri.

Tressoldi, P. E., \& Vio, C. (1996). Diagnosi dei disturbi dell'apprendimento scolastico. Trento: Erickson.

Westen, D. (1991a). Clinical assessment of object relations using the TAT. Journal of Personality Assessment, 56(1), 56-74.

Westen, D. (1991b). Social cognition and object relations. Psychological Bulletin, 109(3), 429-455.

Westen, D., Klepser, J., Ruffins, S. A., Silverman, M., Lifton, N., \& Boekamp, J. (1991). Object relations in childhood and adolescence: The development of working representation. Journal of Consulting and Clinical Psychology, 59(3), 400-409.

Westen, D., Lohr, N., Silk, K. R., Gold, L., \& Kerber, K. (1990). Object relations and social cognition in borderline, major depressives and normals: A thematic apperception test analysis. Psychological Assessment: A Journal of Consulting and Clinical Psychology, 2(4), 355-364.

White, R. W. (1959). Motivation reconsidered: The concept of competence. Psychological Review, 66, 297-333. 